\title{
Modeling the diurnal tide with dissipation derived from UARS/HRDI measurements
}

\author{
M. A. Geller ${ }^{1}$, V. A. Yudin ${ }^{1}$, B. V. Khattatov ${ }^{2}$, M. E. Hagan ${ }^{2}$ \\ ${ }^{1}$ State University of New York at Stony Brook, Stony Brook, New York, USA \\ ${ }^{2}$ National Center for Atmospheric Research, Boulder, Colorado, USA
}

Received: 11 October 1996 / Revised: 2 June 1997 / Accepted: 9 June 1997

\begin{abstract}
This paper uses dissipation values derived from UARS/HRDI observations in a recently published diurnal-tide model. These model structures compare quite well with the UARS/HRDI observations with respect to the annual variation of the diurnal tidal amplitudes and the size of the amplitudes themselves. It is suggested that the annual variation of atmospheric dissipation in the mesosphere-lower thermosphere is a major controlling factor in determining the annual variation of the diurnal tide.
\end{abstract}

\section{Introduction}

The diurnal tide in the mesosphere-lower thermosphere (MLT) region has received a good deal of attention in recent years. Some of this is due to its observed prominence in the HRDI/WINDII observations (see, e.g., Morton et al., 1993; Hays et al., 1994; McLandress et al., 1996) while another factor is recent advancement in modeling the diurnal tide and its annual variation (Hagan et al., 1995a). There have also been recent attempts to combine observations and models to derive a climatology of the diurnal tide (Khattatov et al., 1997a, b).

The purposes of this paper are to try to resolve some of the apparent discrepancies between observations and model results for the diurnal tide and to gain some insight into the atmospheric processes that control its variation. In Sect. 2, some of these previous model and observational results will be presented. Section 3 shows some new modeling results in comparison with observations. Section 4 discusses the results, and Sect. 5 gives the conclusions of this paper.

Correspondence to: M. A. Geller (mgeller@ccmail.sunysb.edu)

\section{Observations and model results for the diurnal tide}

Early HRDI observations on UARS clearly showed that the diurnal tide dominates the low-latitude wind fields at $90 \mathrm{~km}$ (Morton et al., 1993). More detailed analysis of the HRDI data by Hays et al. (1994) showed some of the quantitative features of the diurnal tide in these data. For instance, Fig. 1 (adapted from Hays et al., 1994) shows that the $(1,1)$ diurnal tidal mode at $90 \mathrm{~km}$ is observed to maximize during the periods OctoberNovember and March-April, 1992, with the amplitude maxima of the diurnal variation in northward wind velocities being about $80 \mathrm{~m} \mathrm{~s}^{-1}$. This semiannual variation in the diurnal tidal amplitude had been pointed out earlier in radar wind measurements by Vincent et al. (1989); it should be noted, however, that their model results and observations have, at most, about half the amplitude shown in Fig. 1. Vincent et al. (1989) pointed out that the model simulations should be very sensitive to the dissipation being used in the models and that "studies of the diurnal tide at low-mid-latitudes will themselves lead to improved understanding of the effects of dissipation" (Forbes and Vincent, 1989).

Hagan et al. (1995a,b) have presented their new modeling results on the annual variation of the diurnal tide. Their formulation is based upon the linear tidal model of Forbes (1982). It utilizes Groves' (1982) tabulations for the tropospheric tidal forcing, and the stratospheric and mesospheric tidal heating is based upon the parameterization of Strobel (1978), using updated inputs. The dissipation includes ion drag, molecular and eddy viscosity and conductivity, radiative damping, and a formulation for gravity wave drag. The molecular viscosity and conductivity, ion drag, and radiative damping are as discussed in Hagan et al. (1993) and Forbes (1982). The values of the eddy viscosity and conductivity are based on the monthly climatology calculated by Garcia and Solomon (1985), with the effects of molecular diffusion and the breaking diurnal tide removed. The effective Rayleigh friction that was derived for the effects of gravity wave drag on the 
diurnal tide by Miyahara and Forbes (1991) is used. Figure 2 shows the January, April, July, and October diurnal amplitudes (from Hagan et al., 1995a).

Figure 3 shows the comparison of the diurnal amplitudes and phases for the diurnal tidal variation in the northward wind near $20^{\circ} \mathrm{N}$ (the amplitude of the $(1,1)$-mode of the northward velocity maximizes at $22^{\circ}$ ) in April with that derived from HRDI measurements for April 1992, assuming a pure (1,1)-modal variation, and with MF radar measurements at Kauai, Hawaii, during April 1992. One sees that the HRDI amplitudes are the largest and the radar amplitudes the smallest, with the model results in between. (It should be pointed out that while the amplitudes show some disagreement, the phases agree very well.) Furthermore, the dashed line in Fig. 1 shows the annual variations of the diurnal tidal variations in the northward wind from the model of Hagan et al. (1995a). Basically, one sees that the Hagan et al. (1995a) model results show larger amplitudes than observed by HRDI during the solstitial seasons and smaller amplitudes during the equinoctial seasons. Thus, the model results show a smaller annual variation of the diurnal tide than that observed by HRDI.

\section{The new model results}

Khattatov et al. (1997a,b) have developed a new method for extracting tidal structures from the UARS/HRDI observations. They use a linearized tidal model which is similar in structure to that of Hagan et al. (1995a) but with more simplifications, together with the HRDI data in the following manner. First, the tidal model is used to solve for the diurnal tide using climatological estimates for the mean zonal wind and temperature structures. The modeled diurnal variations in the meridional velocity component are then compared with the diurnal variation of the meridional wind component from the UARS/HRDI measurements over a month. Quite good

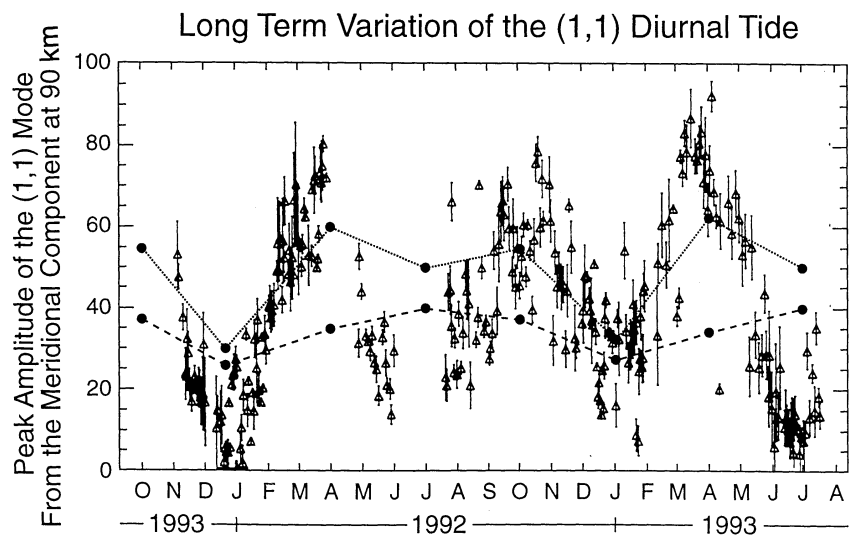

Fig. 1. Time-series of the estimated $(1,1)$ meridional amplitude at $90 \mathrm{~km}$ (after Hays et al., 1994). The dashed curve shows results from the calculations of Hagan et al. (1995a), while the dotted curve shows results using the same model but with the dissipation inferred by Khattatov et al. (1997b). The peak amplitude of the $(1,1)$ meridional tidal velocities occurs at about $+22^{\circ}$ latitude agreement is found between the modeled and observed phases, with less agreement between the amplitudes. First, the modeled phases are adjusted to agree with the UARS/HRDI observed values, where they are available. This is then followed by an adjustment in the amplitudes. By this procedure, a climatology for the diurnal variation in the meridional wind component is derived that is in reasonable agreement with the UARS/HRDI observations and shows the general global behavior of the model results. By these means, the diurnal variation in the meridional wind component is determined. This is used together with the governing equations (equations of motion, thermodynamics, continuity, and state) in an iterative scheme to determine the other diurnal tidal variables (zonal wind, vertical wind, temperature, density, and pressure) and to correct the first guess for the meridional winds to be consistent with the governing equations. These are then used in the tidal energy equation to derive the implied atmospheric dissipation. More details on these procedures are in Khattatov et al. (1997a, b).

Khattatov et al. (1997a) used dissipation in the form of equal coefficients for Rayleigh friction and Newtonian cooling to make their model calculations less computationally demanding. Therefore, Khattatov et al. (1997b) obtained the implied Rayleigh friction and Newtonian cooling coefficients and derived the implied diffusion term, $K_{z z}$, by determining the local vertical wavelength from the derived phases for the diurnal tide and dividing the Rayleigh friction coefficient by the vertical wavenumber squared. These distributions of $K_{z z}$ are shown in Fig. 4. Note that these values of $K_{z z}$ include the effects of all of the dissipation mechanisms in that they supply sufficient dissipation to make the diurnal tidal structure consistent with observations. Note that the values of $K_{z z}$ increase upward and are, in general, larger in the winter hemisphere than in summer. We have highlighted the $200 \mathrm{~m}^{2} \mathrm{~s}^{-1}$ contour since Forbes and Vincent (1989) have suggested that at the altitude where this value is reached the diurnal tide will cease growing and decay above. The Khattatov et al. (1997a, b) diurnal tidal amplitudes and the $K_{z z}$ values in Fig. 4 are generally consistent with this result, except for June and July. The tidal and atmospheric dissipation structures are much more uncertain during these months since we have less data for this time (because of satellite and instrumental malfunctions).

While Hagan et al. (1995a) used the best of their knowledge of atmospheric processes in determining the parameters used in their modeling, some specifications are quite uncertain. In particular, Yudin et al. (1997a) argue that gravity-wave parameterizations have been mostly constrained by fitting the mean zonal winds and temperatures at middle and high latitudes and that the new UARS/HRDI observations of the diurnal tide represent a unique constraint on the atmospheric dissipation at low latitudes (between about $30^{\circ}$ north and south). Thus, we have tried the following numerical experiment. We removed all of the specifications of atmospheric dissipation in the Hagan et al. (1995a) model and replaced them with the determination of $K_{z z}$ 

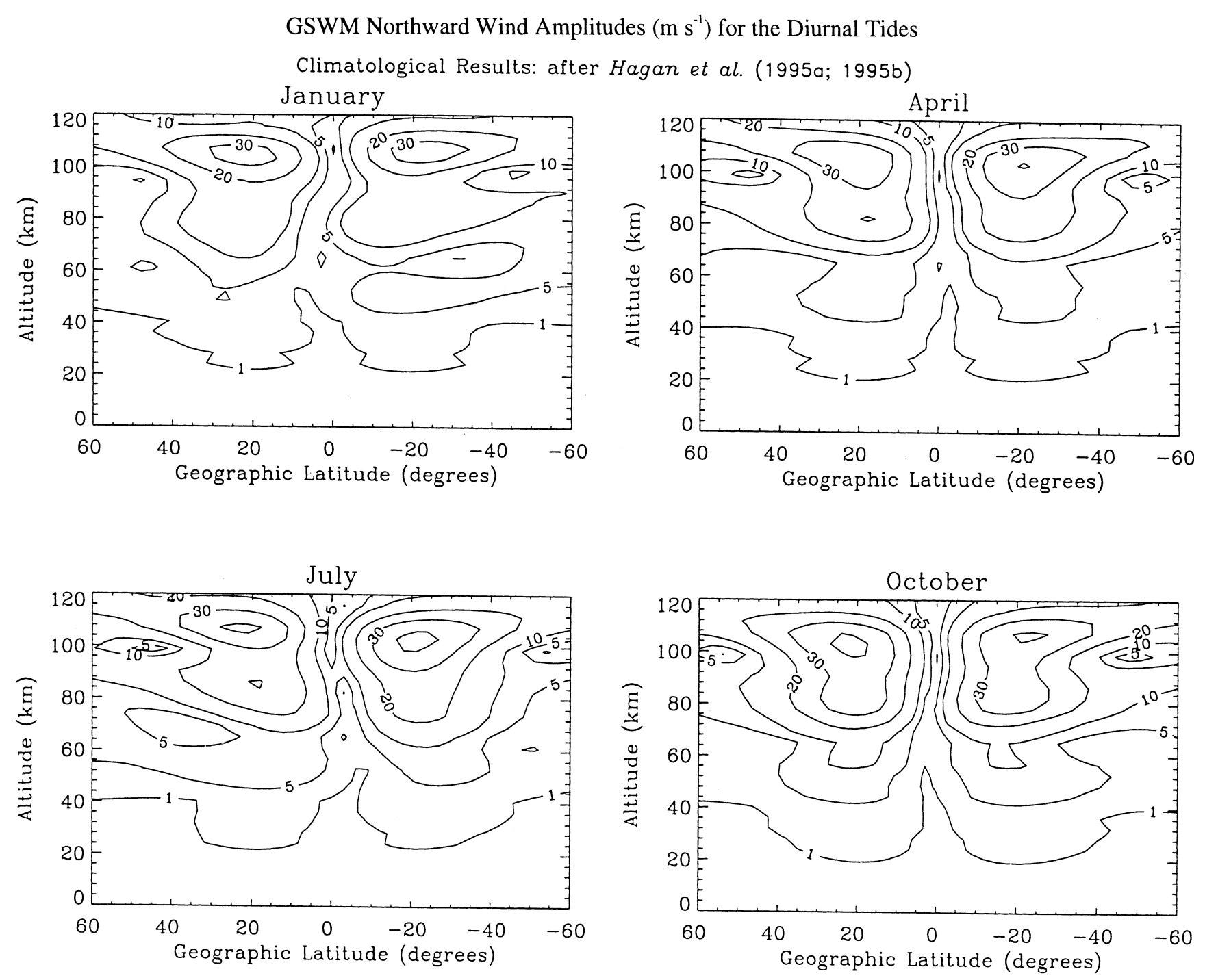

Fig. 2. Meridional wind amplitudes $\left(\mathrm{m} \mathrm{s}^{-1}\right)$ from calculations for the diurnal tide of Hagan et al. (1995a)

in Khattatov et al. (1997b) in both the momentum and thermodynamic equations. Figure 5 shows the amplitudes for the diurnal variation of the northward velocity component derived in this manner. Comparing this to the earlier results of Hagan et al. (1995a) shows the following. The January tidal amplitudes shown in Fig. 5 have a bit more hemispheric asymmetry with maximum amplitudes in the southern (summer) hemisphere, but the general January amplitudes are quite similar in Figs. 2 and 5. The April amplitudes in Fig. 5 are much larger than those in Fig. 2, by almost a factor of 2. The July results in Fig. 5 are also much larger than those in Fig. 2, but it should be noted that Khattatov et al. (1997a) have indicated that their derived tidal structures, and the resulting dissipation, during this month are probably spurious due to less data being available and possible contamination by the nontidal motions. Finally, the October results in Fig. 5 are significantly larger than those in Fig. 2, by about $25 \%$. It is clear from this comparison that the Hagan et al. model gives both higher tidal amplitudes and a larger annual variation when their previous specifications of the tidal dissipation are replaced with the Khattatov et al. values. This can been seen in a different way by comparing the dotted curve [representing the Hagan et al. (1995a) calculations with the Khattatov et al. (1997b) dissipation] and the dashed curve [representing the original Hagan et al. (1995a) results], in Fig. 1. In this figure, the Hagan et al. values were determined by averaging the amplitudes at $\pm 22^{\circ}$, the latitudes where the $(1,1)$-mode of the diurnal northward velocity peaks. It is clear that the new calculations give much better agreement with HRDI observations.

\section{Discussion of results}

The main conclusion of this paper is that it is probably the incorrect specification of atmospheric dissipation which is responsible for the inability of first-principle tidal models to determine correctly the annual variation and amplitude of the diurnal tide in the MLT region. 
Diurnal Tidal Signatures near $20^{\circ} \mathrm{N}$ during April

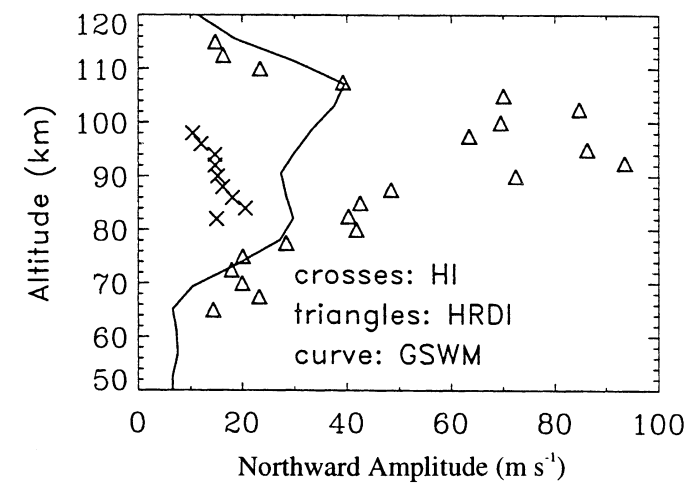

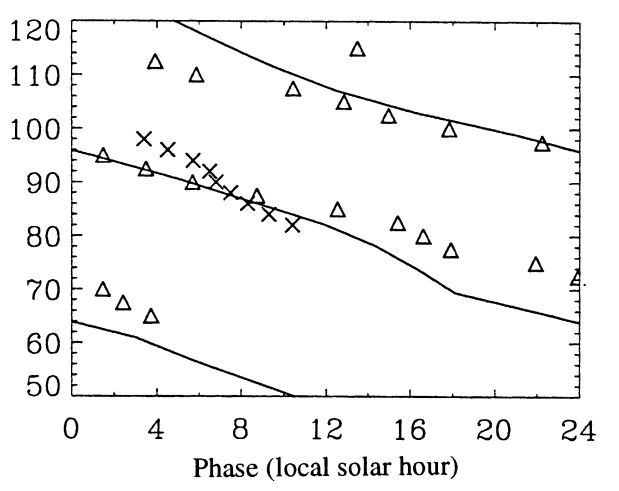

Fig. 3. Northward wind amplitudes (left) and phases (right) from the model of Hagan et al. (1995a) for April at $21^{\circ} \mathrm{N}$ and monthly averaged UARS/ HRDI data (triangles) for April 1992, and MF radar measurements (crosses) over Kauai, Hawaii $\left(20^{\circ} \mathrm{N}\right)$, for April 1992. From Hagan et al. (1995b)
This is not a surprising result. Yudin et al. (1997a) have pointed out that there have been very few observational constraints on atmospheric dissipation, in general, and gravity-wave parameterization, in particular, at low latitudes. As was pointed out earlier, Vincent et al. (1989) indicated that they believed that studies of the diurnal tide would lead to a greater understanding of atmospheric dissipation. Having said this, however, more discussion is needed to place the present results in a proper context.

Referring to Figure 3, we see that there is a great difference in the structure of the diurnal tide that is derived from UARS/HRDI observations from that derived from MF radar observations. Namely, according to UARS/HRDI measurements, the diurnal tide reaches higher amplitude and maximizes at higher altitudes. This is a consequence of the negative wind speed bias in MF radar measurements relative to UARS/HRDI measurements above about $85-\mathrm{km}$ altitude (e.g., Burrage et al., 1996; Khattatov et al., 1996). Obviously then, if one repeated the exercise of deriving the implied atmospheric dissipation from MF radar measurements (instead of HRDI measurements), greater atmospheric dissipation would be found at MLT altitudes. Several workshops have been held to try to resolve the differences in wind measurements from UARS and MF radars. According to Cervera and Reid (1995), depending on operational parameters, MF radars also show a negative wind speed bias relative to meteor radar measurements. Also, UARS wind measurements appear to be consistent with the diurnal variations in green-line airglow that have been seen in WINDII data by Shepherd et al. (1995). Modeling results suggest that the diurnal tide with amplitudes derived from the HRDI and WINDII measurements on UARS will produce the observed diurnal variation in green-line airglow while the diurnal tide derived from MF radar measurements will not (Roble, personal communication).

The calculations presented in this paper rely on something of a circular argument; that is to say, that tidal calculations using the atmospheric dissipation derived to be consistent with UARS measured tides give tidal structures that also agree with UARS observations. We acknowledge this point, but the main conclusion of this paper is that the dissipation formulations being used in state-of-the-art first-principle tidal models give results that are at variance with observations (too small diurnal tidal amplitudes and not enough annual variation) and are probably incorrect. Annual variations in the tidal forcing and the mean winds and temperature structure will also give rise to annual variations in the diurnal tide; however, both sets of the calculations in this paper using the Hagan et al. (1995a) model used the same values for these parameters for each given month. Thus, it was only the changed dissipation in these models that gave the improved agreement with observations. Of course, if there are errors in the assumed tidal forcings, this would imply that our derived dissipation is also incorrect. There are some uncertainties in the tidal forcings. For instance, the Groves (1982) tropospheric forcing calculations used very simplified representations of upper-tropospheric water vapor.

Nevertheless, we feel that the mean wind and temperature state of the atmosphere and the tidal forcings are much better known than the atmospheric dissipation. Our estimates of the atmospheric dissipation should be regarded only as a refined estimate, however, until these other parameters (mean state and tidal forcings) are better determined.

Finally, the tidal structures and atmospheric dissipation calculated by Khattatov et al. (1997a, b) used UARS/HRDI data for the two years 1992 and 1993, and thus cannot address issues of year-to-year tidal variability, such as have been presented by Burrage et al. (1995), for example. Two years of data were used in deriving the diurnal tidal structure by Khattatov et al. (1997a, b) to get more dependable statistics for the observations, so their results must be viewed as being relevant to a mean climatology for those two years. Thus, for example, the model comparisons in Fig. 1 are really between the ensemble of daily observations and models results for the climatological structure of the diurnal tide. For this reason, we would not expect the modeling results to reproduce the extremes of the observations.

\section{Conclusions}

We have presented tidal calculations using a state-ofthe-art tidal model using (1) best first-principle guesses 

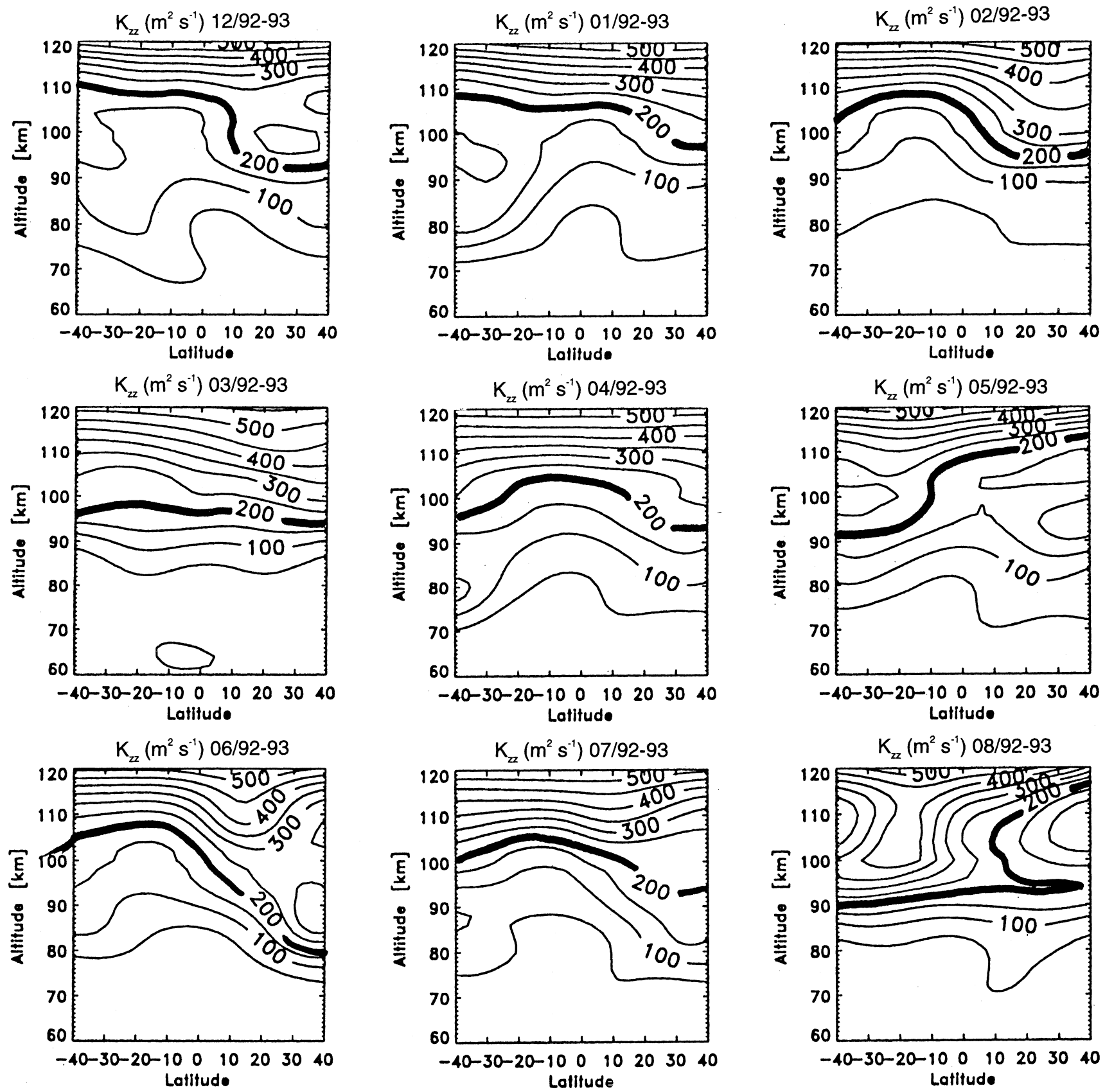

$\mathrm{K}_{\mathrm{zz}}\left(\mathrm{m}^{2} \mathrm{~s}^{-1}\right)$ 08/92-93
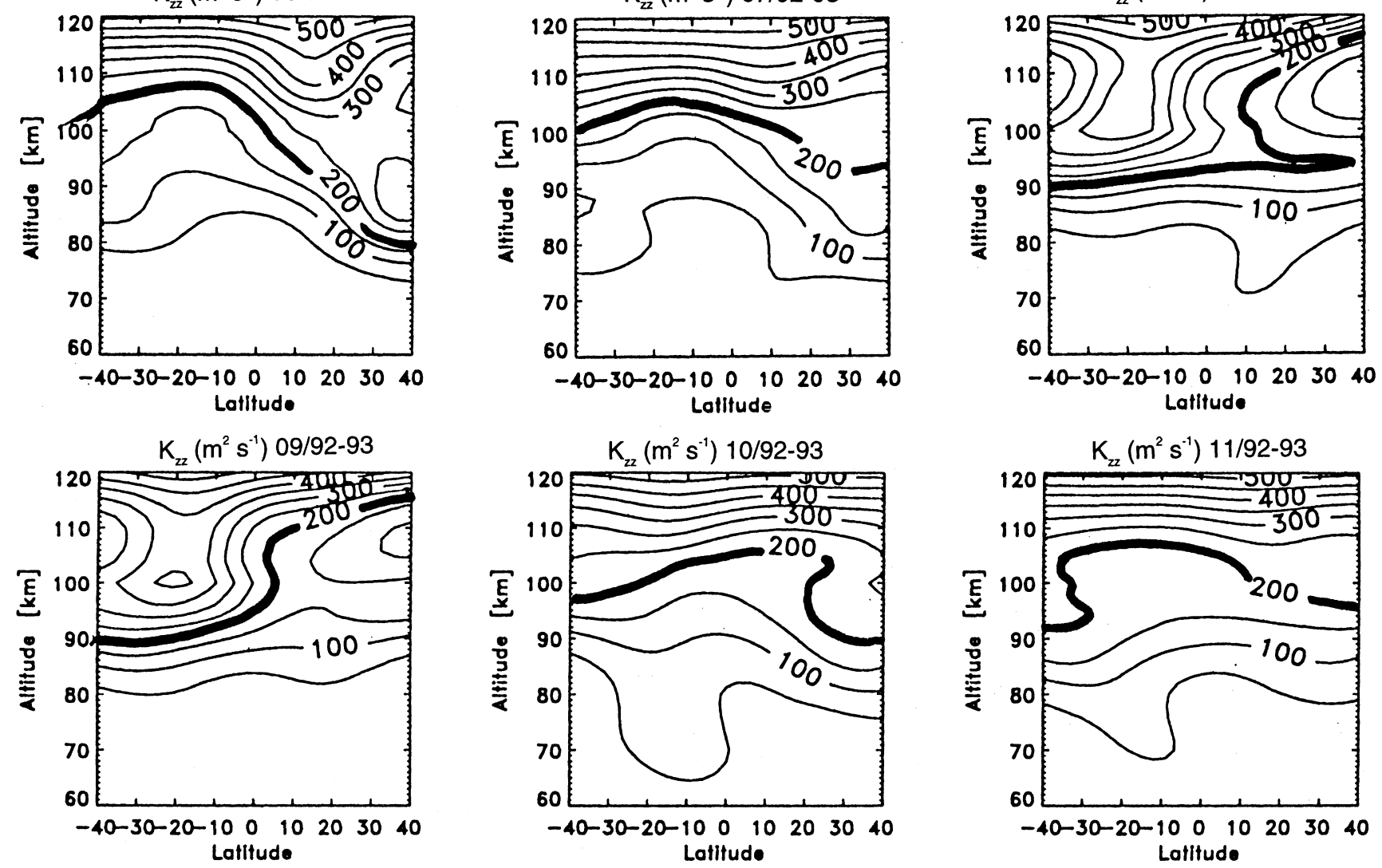

Fig. 4. Monthly mean vertical turbulent diffusion coefficients inferred from HRDI data for 1992-1993 by Khattatov et al. (1997b) 


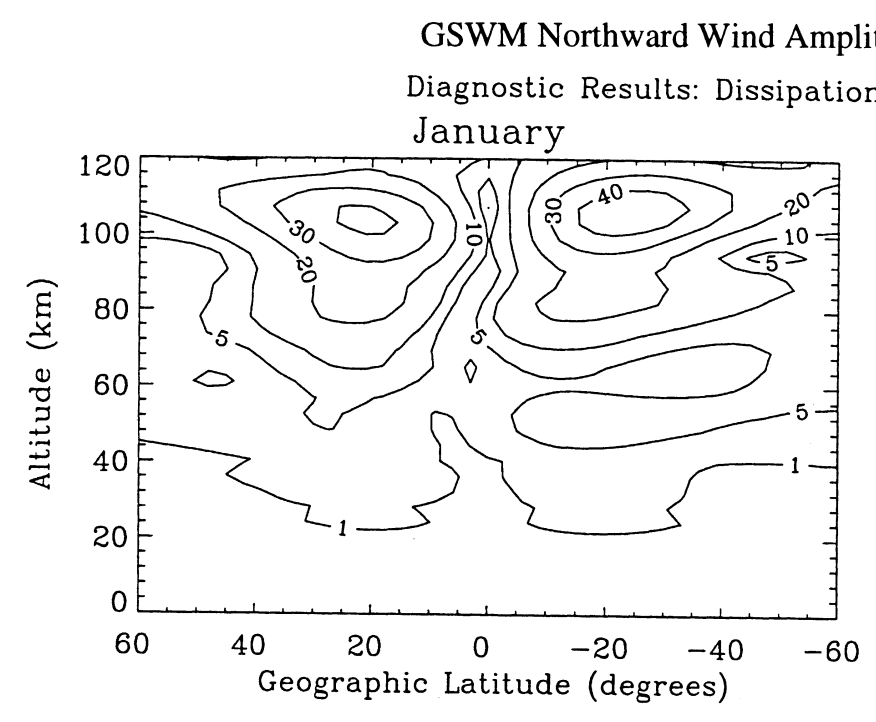

after Khattatov et al. (1997b)
(19)
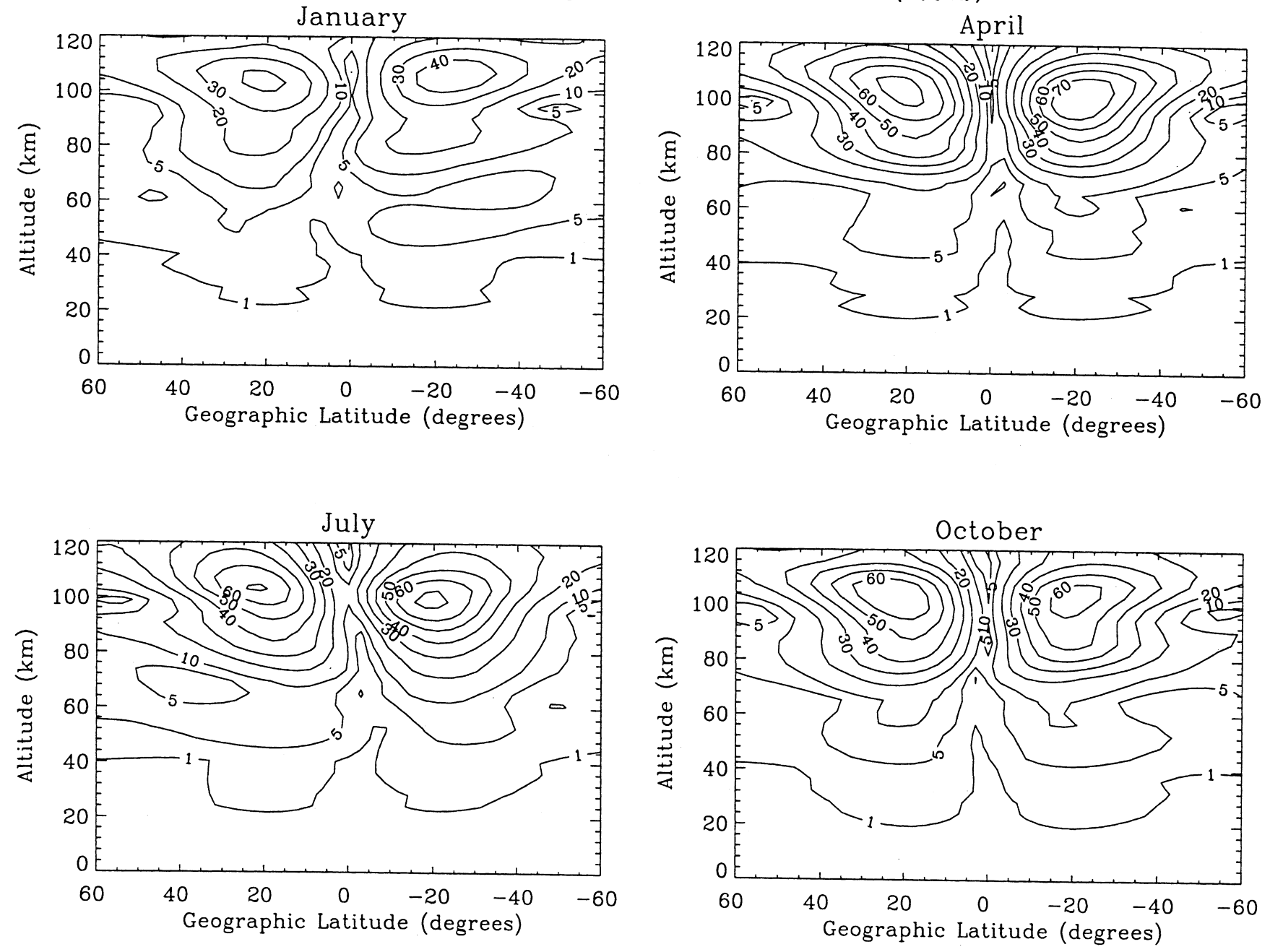

Fig. 5. Meridional wind amplitudes $\left(\mathrm{m} \mathrm{s}^{-1}\right)$ from calculations using the Hagan et al. (1995a) model for the diurnal tide using the Khattatov et al. (1997b) inferred atmospheric dissipation

for the tidal dissipation parameters and (2) dissipation derived from UARS/HRDI observations of the diurnal tide. The better agreement with observations using the HRDI-derived dissipation suggests that the specifications of atmospheric dissipation used in state-of-the-art tidal models excessively damp the MLT diurnal tide and do not vary sufficiently throughout the year to give results in agreement with observations. This implies that those specifications of the atmospheric dissipation in the MLT region are probably incorrect. These results have broader implications than just obtaining better results in tidal models. Improved estimates for atmospheric dissipation also give some constraints on gravity wave parameterizations (Yudin et al., 1997a). They also have implications on constituent mixing as well as on the temperature structure in the MLT region. Yudin et al. (1997b) also consider the effects of the revised atmospheric dissipation on the semidiurnal tide.
Acknowledgements. The research reported here was carried out at the State University of New York at Stony Brook and at the National Center for Atmospheric Research (NCAR). The Stony Brook research was supported by NASA's UARS project, and the NCAR research was partially supported by NASA grant \# S-97239-

E. NCAR is sponsored by the National Science Foundation.

Topical Editor F. Vial thanks two referees for their help in evaluating this paper.

\section{References}

Burrage, M. D., M. E. Hagan, W. R. Skinner, D. L. Wu, and P. B. Hays, Long-term variability in the solar diurnal tide observed by HRDI and simulated in the GSWM, Geophys. Res. Lett., 22, 2641-2644, 1995.

Burrage, M. D., W. R. Skinner, D. A. Gell, P. B. Hays, A. R. Marshall, D. A. Ortland, A. H. Manson, S. J. Franke, D. C. Fritts, P. Hoffman, C. McLandress, R. Niciewjewski, F. J. Schmidlin, G. G. Shepherd, W. Singer, T. Tsuda, and R. A. 
Vincent, Validation of mesosphere and lower thermosphere winds from the high-resolution Doppler imager on UARS. J. Geophys. Res., 101, 10365-10392, 1996.

Cervera, M. A., and I. M. Reid, Comparison of simultaneous wind measurements using colocated VHF meteor radar and MF spaced antenna radar systems. Radio Sci., 30, 1245-1261, 1995.

Forbes, J. M., Atmospheric tides, 1, model description and results for the solar diurnal component, J. Geophys. Res., 87, 52225240, 1982.

Forbes, J. M., and R. A. Vincent, Effects of mean winds and dissipation on the diurnal propagating tide: an analytic approach, Planet. Space Sci., 37, 197-209, 1989.

Garcia, R. R., and S. Solomon, The effect of breaking gravity waves on the dynamics and chemical composition of the mesosphere and lower thermosphere, J. Geophys. Res., 90, 3850-3868, 1985.

Groves, G. V. Hough components of water vapor heating, J. Atmos. Terr. Phys., 44, 281-290, 1982.

Hagan, M. E., J. M. Forbes, and F. Vial, A numerical investigation of the propagation of the quasi 2-day wave into the lower thermosphere, J. Geophys. Res., 98, 23193-23205, 1993.

Hagan, M. E., J. M. Forbes, and F. Vial, On modeling migrating solar tides, Geophys. Res. Lett., 22, 893-896, 1995a.

Hagan, M. E., J. M. Forbes, and F. Vial, An updated model of migrating tides in the middle atmosphere: inertial results and measurement campaigns, Worksh Wind Observations in the Middle Atmosphere, 15-18 November 1994, CNES-HQ, Paris, 1995 b.

Hays, P. B., D. L. Wu, M. D. Burrage, D. A. Gell, H. J. Grassal, R. S. Lieberman, A. R. Marshall, Y. T. Morton, D. A. Ortland, and W. R. Skinner, Observations of the diurnal tide from space, J. Atmos. Sci., 51, 3077-3093, 1994.

Khattatov, B. V., M. A. Geller, V. A. Yudin, P. B. Hays, W. R. Skinner, M. D. Burrage, S. J. Franke, D. C. Fritts, J. R. Isler, A. H. Manson, C. E. Meek, R. McMurray, W. Singer, P. Hoffmann, and R. A. Vincent, Dynamics of the mesosphere and lower thermosphere as seen by MF radars and by the high-resolution Doppler imager/UARS. J. Geophys. Res., 101, 10393-10404, 1996.
Khattatov, B. V., M. A. Geller, V. A. Yudin, P. B. Hays, and R. A. Vincent, Diurnal migrating tide as seen by HRDI/UARS. Part 1: monthly mean global meridional winds, J. Geophys. Res., 102, 4405-4422. 1997a.

Khattatov, B. V., V. A. Yudin, M. A. Geller, and P. B. Hays, Diurnal migrating tide as seen by HRDI/UARS. Part 2: monthly mean global zonal and vertical velocities, pressure, and temperature and inferred dissipation, J. Geophys. Res., 102, 4423-4435, 1997b.

McLandress, C., G. G. Shepherd, and B. H. Solheim, Satellite observations of thermospheric tides: results from the Wind Imaging Interferometer on UARS, J. Geophys. Res., 101, $4093-$ 4114, 1996.

Miyahara, S., and J. M. Forbes, Interaction between gravity waves and the diurnal tide in the mesosphere and lower thermosphere, J. Meteor. Soc. Japan, 69, 523-531, 1991.

Morton, Y. T., R. S. Lieberman, P. B. Hays, D. A. Ortland, A. R. Marshall, D. Wu, W. R. Skinner, M. D. Burrage, D. A. Gell, and J. H. Yee, Mesospheric tidal winds observed by the HighResolution Doppler Imager on board the Upper-Atmosphere Research Satellite, Geophys. Res. Lett., 20, 1263-1266, 1993.

Shepherd, G. G., C. McLandress, and B. H. Solheim, Tidal influence on $\mathrm{O}\left({ }^{1} \mathrm{~S}\right)$ airglow emission rate distributions at the geographic equator as observed by WINDII, Geophys. Res. Lett., 22, 275278, 1995 .

Strobel, D. F., Parameterization of the atmospheric heating rate from 15 to $120 \mathrm{~km}$ due to $\mathrm{O}_{2}$ and $\mathrm{O}_{3}$ absorption of solar radiation, J. Geophys. Res., 83, 6225-6230, 1978.

Vincent, R. A., T. Tsuda, and S. Kato, Asymmetries in mesospheric tidal structure, J. Atmos. Terr. Phys., 51, 609-616, 1989.

Yudin, V. A., M. A. Geller, and B. V. Khattatov, Estimate of atmospheric dissipation derived from UARS/HRDI measurements, to appear in Gravity wave processes and their parameterization in global climate models, K. Hamilton (ed.), Springer, Berlin, Heidelberg, New York, 1997a.

Yudin, V. A., B. V. Khattatov, M. A. Geller, D. A. Ortland, C. McLandress, and G. G. Shepherd, Thermal tides and studies to tune the mechanistic tidal model using UARS observations, Ann. Geophysicae. 15, this issue, 1997b. 